\title{
Analyzing the Cooling Rate and Its Effect on Distribution of Pattern and Size of the Titanium Diboride Particles Formed
}

\author{
P. Senthil Kumar ${ }^{1},{ }^{1}$ Pon Selvan Chithirai, ${ }^{2}$ D. Antony Prabu, ${ }^{3}$ G. Surya Prakash, \\ V. Murali Krishna, ${ }^{1}$ and Jemal Yimer Mohammed ${ }^{5}{ }^{5}$ \\ ${ }^{1}$ Department of Mechanical Engineering, B. V. Raju Institute of Technology, Narsapur, Telangana, India \\ ${ }^{2}$ Head of School, Science and Engineering, Curtin University Dubai, Dubai, UAE \\ ${ }^{3}$ Department of Mechanical Engineering, Loyola-ICAM College of Engineering and Technology, Chennai, India \\ ${ }^{4}$ Department of Mechanical Engineering, Marri Laxman Reddy Institute of Technology and Management, Hyderabad, India \\ ${ }^{5}$ Department of Mechanical Engineering, WOLLO University, Kombolcha Institute of Technology, \\ Kombolcha, Ethiopia Post Box No: 208
}

Correspondence should be addressed to Jemal Yimer Mohammed; jemalm@kiot.edu.et

Received 7 October 2021; Revised 3 November 2021; Accepted 6 November 2021; Published 10 December 2021

Academic Editor: Adam Khan M

Copyright (C) 2021 P. Senthil Kumar et al. This is an open access article distributed under the Creative Commons Attribution License, which permits unrestricted use, distribution, and reproduction in any medium, provided the original work is properly cited.

\begin{abstract}
In this work, we synthesize $\mathrm{Al} / \mathrm{TiB}_{2}$ metal matrix composites (MMC) based on the effect of cooling rate in the melt while pouring into the permanent mold condition. The objective of this paper is to achieve the desired distribution pattern and increased $\mathrm{TiB}_{2}$ particles' size in the $\mathrm{Al} / \mathrm{TiB}_{2} \mathrm{MMC}$ ingot. Two halide salts, viz., potassium hexafluorotitanate $\left(\mathrm{K}_{2} \mathrm{TiF}_{6}\right)$ and potassium tetrafluoroborate $\left(\mathrm{KBF}_{4}\right)$, are procured and measured. The two salts were mixed with the aluminium melt in the crucible, and it is stirred manually with help of a graphite rod. Because of the exothermic reaction, the melt reacts very quickly and that is what dropped the salts slowly. The salt particles were synthesized because of the exothermic reaction, and it will allow the particles to grow. The size and distribution of particles differ at different place in the MMC. An FEA tool ProCAST was used to analyze the cooling rate of the melt, and SEM is used to study the microstructure of the ingot at different places. The microstructures helped to identify the size of reinforcement in the $\mathrm{MMC}$. The $\mathrm{TiB}_{2}$ particles are distributed more at this location at $810^{\circ} \mathrm{C}$, and the $\mathrm{TiB}_{2}$ particles formed various clusters in this zone as $70 \%-80 \%$. Also, the tribological characteristics are analyzed with the help of the results.
\end{abstract}

\section{Introduction}

The cast aluminium components are used in automotive industries due to its more strength-weight ratio, outstanding castability, and corrosion resistance $[1,2]$. The ex situ method is involved for the fabrication of particulate matter reinforced metal matrix composites (PRMMCs) by conventional ex situ method due to its isotropic properties, ease of fabrication, and the lower cost. The reinforcement is added directly to fabricate the ex situ composites $[3,4]$. In in situ method, a chemical reaction of reinforcements inside the composites takes place to synthesize the composites. To identify the behavior of in situ particles, a small work was carried out in the aluminium matrix composites [5].
The in situ metal matrix composites have a good attraction characteristic because of their good bonding strength and well distribution of fine reinforcement $[6,7]$. It was found that the study was concentrated on fabrication and the mechanical properties of the reinforcement such as $\mathrm{SiC}, \mathrm{Al}_{2} \mathrm{O}_{3}, \mathrm{TiC}$, and $\mathrm{B}_{4} \mathrm{C}$. Various researchers have performed high-performance applications focusing on TiB2 as the reinforcement as of its high elastic modulus and high thermal conductivity $[8,9]$. Also, it does not react with the molten aluminium. The casting defects such as oxide films, porosity, and other inclusions will strongly disturb the mechanical behavior of the cast aluminium alloys $[10,11]$. However, because of the stiffness, hardness, and improved tensile strength, the aluminium-based MMCs are preferred 
compared to the base matrix alloy [12-14]. The fabrication of aluminium-based MMCs is done by addition of $\mathrm{SiC}, \mathrm{Al}_{2} \mathrm{O}_{3}$, $\mathrm{TiC}, \mathrm{CBN}$, and $\mathrm{TiB}_{2}$. Out of these ceramic-based reinforced particles, $\mathrm{TiB}_{2}$ is used mostly because they possess hardness, maximum tensile strength, and compressive strength $[15,16]$.

Because of the very clean and size of particles in the interface of the in situ method, the fabrication of $\mathrm{Al} / \mathrm{TiB}_{2}$ MMCs is preferred. Also, the increased tensile strength and fatigue strength is due to the very fine particles [17].

In the in situ fabrication method, two salt powders such as $\mathrm{K}_{2} \mathrm{TiF}_{6}$ and $\mathrm{KBF}_{4}$ were used as reinforcement. They were mixed in measured proportion and then poured to the aluminium melt slowly. The mixture was stirred manually to endorse the reaction between salts with the help of a manual graphite rod. The floron gas was inserted in the melt to avoid formation of gases which will create the casting defects such as blow holes $[18,19]$. Later, the melt was kept in hold to synthesize $\mathrm{TiB}_{2}$ particles that grow in size with holding time $[20,21]$.

The $\mathrm{Al} / \mathrm{TiB}_{2}$ melt was poured into the mould, so the falling elevation will be the possible turbulence that occurs during filling. The fragmented $\mathrm{TiB}_{2}$ particles are created due to the turbulence, and also a variation in distribution occurred at different locations. It occurs because the cooling rate and turbulence were attributed and also due to the influence of melt fluidity [22, 23]. The above parameters were analyzed, and their effects are understood clearly from the SEM micrographs captured from the cast ingot at six different locations.

\section{Experimental Work}

An in situ method was used to fabricate $\mathrm{Al} / \mathrm{TiB}_{2}$ MMCs through salt metal reaction. Three different melt temperatures were maintained, such as $750^{\circ} \mathrm{C}, 780^{\circ} \mathrm{C}$, and $810^{\circ} \mathrm{C}$. Also, three dissimilar holding times were maintained after mixing of entire salt such as ten minutes, twenty minutes, and thirty minutes before pouring into the permanent molds. Through the same procedure, totally nine ingots were fabricated with different combinations, pouring temperature, and holding time [24]. The size of the reinforced particle is not the same as in the melt because of the parameters' fluidness and disorder at different places of the ingot and the local cooling rate of the casting [25].

Figure 1(a) shows the twenty-four various locations in cast ingots from top to bottom, and based on variation of local conditions of ingot, six locations were selected from twenty-four various locations. The distribution of $\mathrm{TiB}_{2}$ particles and size were compared for all nine ingots through the SEM micrographs; Figures 1(b)-1(d) show the SEM micrographs.

2.1. Finite Element Analysis. Figure 2(a) shows the simulation model, and Figure 2(b) describes the mesh diagrams of ingot. The temperature vs. time curves were generated at twenty-four different locations of each ingot by using the
FEA tool. Out of the twenty-four different locations, selected six locations were shortlisted for simulation. From the simulation, a drastic variation occurred in the melt due to the turbulence of melt, cooling rate, and fluidness.

Figures 3(a)-3(f) show the temperature vs. time curves at selected six different locations.

\section{Results and Discussions}

At location 23, the temperature-time curve indicates maximum cooling rate and turbulence during filling out of twenty-four different locations. Also, it was found that the fluidness reaches its maximum range at the maximum pouring temperature.

Also, here we discuss the effect of cooling rate at location 23. This location is marked in the bottom surface of the ingot, and the cooling rate and the fluidity are maximum at this location at $810^{\circ} \mathrm{C}$ pouring temperature. Additionally, the falling height of the melt during the filling process is considered to be maximum. Because of the abovementioned reasons, at location 23, the turbulence will be maximum. Because of these reasons, the circulation will be maximum at $810^{\circ} \mathrm{C}$, and it will cause the $\mathrm{TiB}_{2}$ particles to fragment. Hence, the $\mathrm{TiB}_{2}$ particles get entrapped quickly because of maximum cooling rate, and the casting at this location is freezed [26].

Moreover, more $\mathrm{TiB}_{2}$ particles are distributed at this location at $810^{\circ} \mathrm{C}$ and the $\mathrm{TiB}_{2}$ particles formed various clusters in this zone as $70 \%-80 \%$.

Here, we discuss the effect of cooling rate at location 21. This location is marked in the middle surface of the ingot; the cooling rate and the fluidity are modest at this location at $810^{\circ} \mathrm{C}$ pouring temperature. Additionally, the falling height of the melt during the filling process is considered to be average. Because of the abovementioned reasons, at location 21 , the turbulence will be average. Because of these reasons, the circulation will be maximum at $810^{\circ} \mathrm{C}$, and it will cause the $\mathrm{TiB}_{2}$ particles to fragment. Hence, the $\mathrm{TiB}_{2}$ particles get entrapped quickly because of maximum cooling rate, and the casting at this location is freezed [27, 28].

Moreover, more $\mathrm{TiB}_{2}$ particles are distributed at this location at $810^{\circ} \mathrm{C}$ and the $\mathrm{TiB}_{2}$ particles formed various clusters in this zone as $60 \%-70 \%$.

In this paragraph, we discuss the effect of cooling rate at location 19. This location is marked in the top surface of the ingot; the cooling rate and the fluidity are very low at this location at $810^{\circ} \mathrm{C}$ pouring temperature. Additionally, the falling height of the melt during the filling process is considered to be very less. Because of the abovementioned reasons, at location 19 , the turbulence will be average. Because of these reasons, the circulation will be maximum at $810^{\circ} \mathrm{C}$, and it will cause the $\mathrm{TiB}_{2}$ particles to fragment. Hence, the $\mathrm{TiB}_{2}$ particles get entrapped quickly because of very minimum cooling rate, and the casting at this location is freezed. Most of the $\mathrm{TiB}_{2}$ particles were trapped at locations 23 and 21 already. Hence, very small particles settled down in this particular location.

Analyzing at location 1, the falling height and the cooling rate were minimum. Due to the effect, most of the particles 


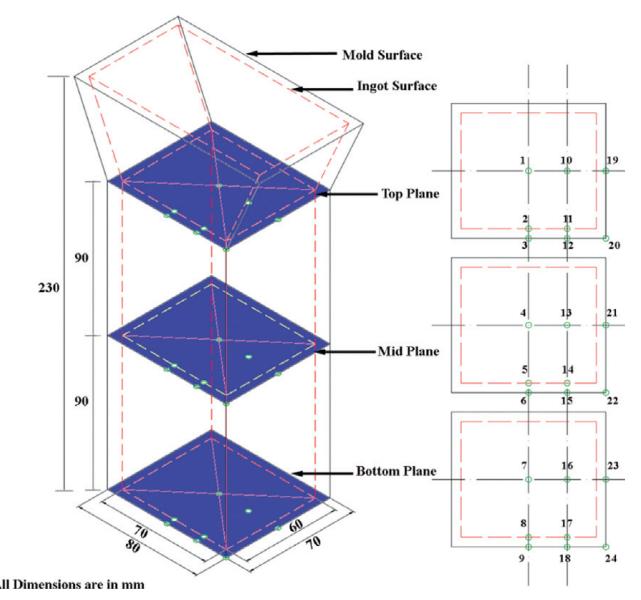

(a)

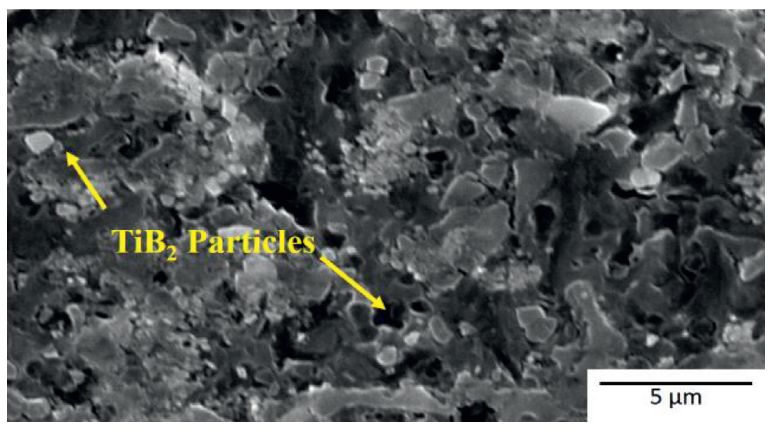

(c)

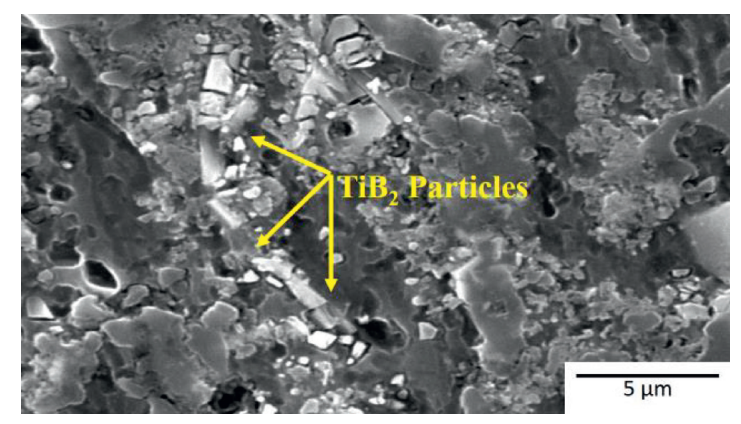

(b)

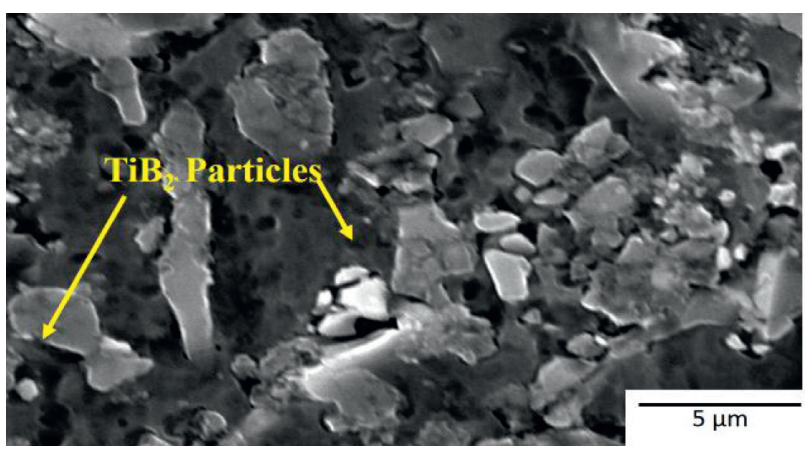

(d)

FIGURE 1: (a) Ingot drawing showing locations considered. SEM micrograph at location 1 of the ingot for (b) $750^{\circ} \mathrm{C}$ pouring temperature and 10 -min holding time, (c) $750^{\circ} \mathrm{C}$ pouring temperature and 20 -min holding time, and (d) $750^{\circ} \mathrm{C}$ pouring temperature and 30 -min holding time.

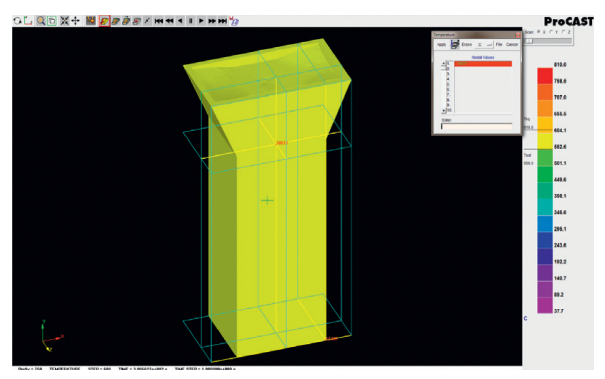

(a)

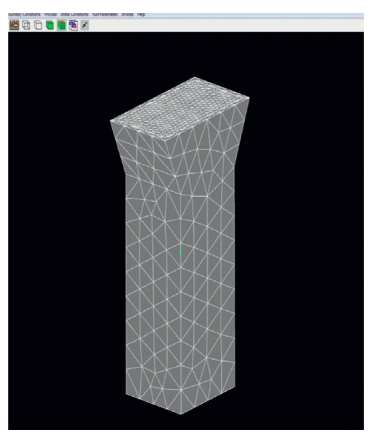

(b)

Figure 2: (a) Mold model. (b) Mold meshing.

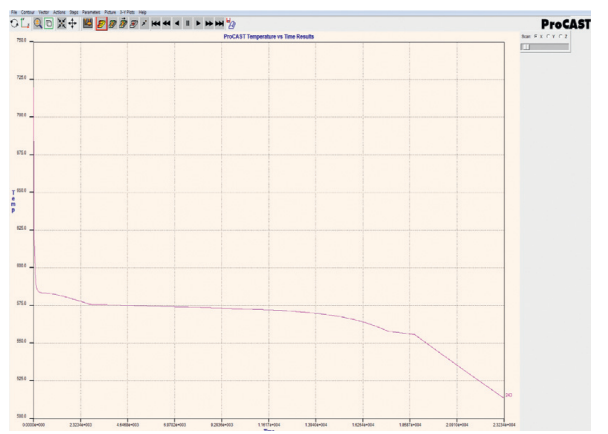

(a)

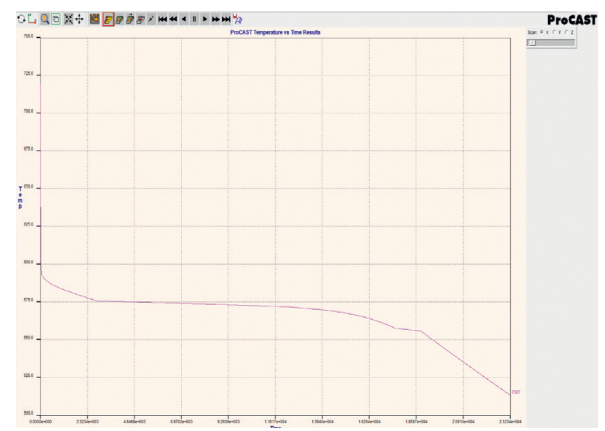

(b)

Figure 3: Continued. 


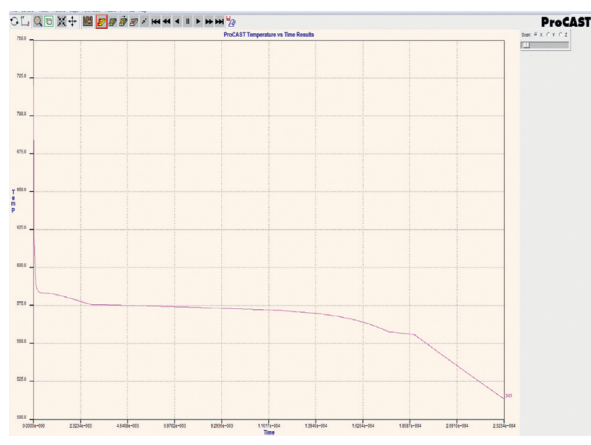

(c)

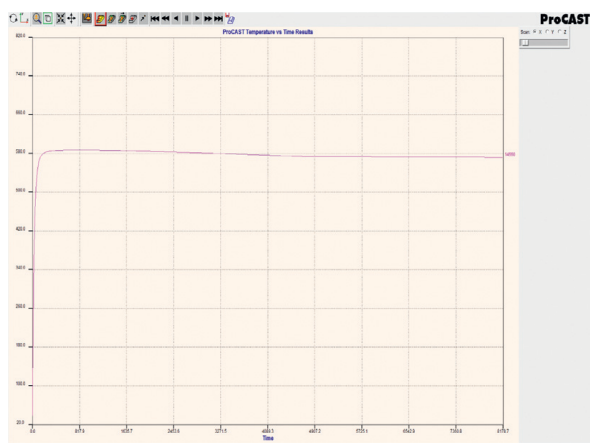

(e)

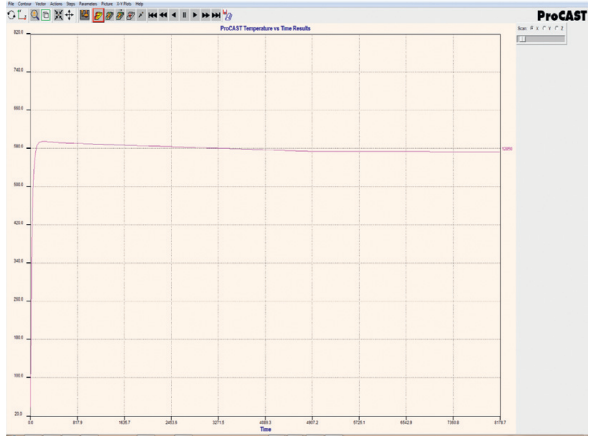

(d)

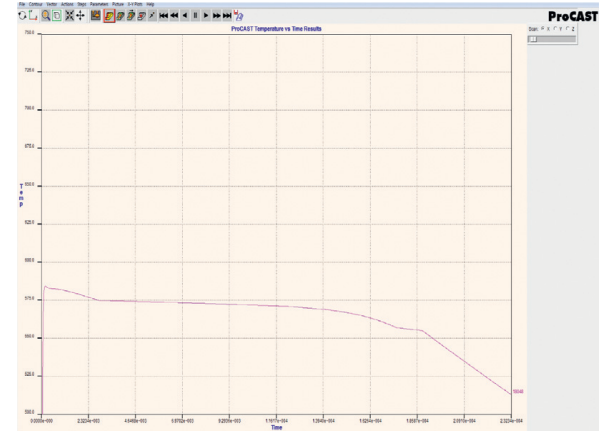

(f)

Figure 3: (a) Tvs. $t$ at point 1 for $750^{\circ} \mathrm{C}$. (b) $T$ vs. $t$ at point 4 for $780^{\circ} \mathrm{C}$. (c) $T$ vs. $t$ at point 7 for $780^{\circ} \mathrm{C}$. (d) $T$ vs. $t$ at point 19 for $780^{\circ} \mathrm{C}$. (e) $T$ vs. $t$ at point 21 for $780^{\circ} \mathrm{C}$. (f) $T$ vs. $t$ at point 23 for $780^{\circ} \mathrm{C}$.

TABLE 1: TiB2\% of different places in micrographs.

\begin{tabular}{|c|c|c|c|c|}
\hline \multirow{2}{*}{ Location } & \multirow{2}{*}{ Pouring temperature (in degree Celsius) } & \multicolumn{3}{|c|}{ Percentage area of $\mathrm{TiB}_{2}$} \\
\hline & & $10 \mathrm{~min}$ & $20 \mathrm{~min}$ & $30 \mathrm{~min}$ \\
\hline \multirow{3}{*}{1} & 750 & $10-20$ & $30-40$ & $35-40$ \\
\hline & 780 & $20-30$ & $30-40$ & $35-40$ \\
\hline & 810 & $20-30$ & $30-40$ & $40-50$ \\
\hline \multirow{3}{*}{4} & 750 & $30-35$ & $30-35$ & $35-40$ \\
\hline & 780 & $20-30$ & $25-35$ & $30-40$ \\
\hline & 810 & $25-30$ & $30-35$ & $40-50$ \\
\hline \multirow{3}{*}{7} & 750 & $10-20$ & $30-40$ & $25-35$ \\
\hline & 780 & $20-30$ & $35-45$ & $40-50$ \\
\hline & 810 & $20-30$ & $40-50$ & $60-70$ \\
\hline \multirow{3}{*}{19} & 750 & $20-30$ & $20-30$ & $30-40$ \\
\hline & 780 & $20-30$ & $40-50$ & $40-50$ \\
\hline & 810 & $20-30$ & $50-60$ & $50-60$ \\
\hline \multirow{3}{*}{21} & 750 & $30-40$ & $20-30$ & $40-50$ \\
\hline & 780 & $10-20$ & $30-40$ & $30-40$ \\
\hline & 810 & $30-40$ & $50-60$ & $60-70$ \\
\hline \multirow{3}{*}{23} & 750 & $30-35$ & $35-40$ & $40-50$ \\
\hline & 780 & $35-40$ & $45-50$ & $50-60$ \\
\hline & 810 & $40-50$ & $60-70$ & $70-80$ \\
\hline
\end{tabular}

were trapped at the bottom of the ingot at location 1 , which was found to have fewer TiB2 particles through SEM micrographs. Also, it covers $40 \%-50 \%$ area in the SEM micrograph.
The friction between the aluminium matrix and TiB2 particles was analyzed. The tribological characteristics showed better performance than conventional material. 
TABle 2: TiB2\% particle size for holding time.

\begin{tabular}{|c|c|c|c|c|}
\hline \multirow[b]{2}{*}{ Position } & \multirow{2}{*}{$\begin{array}{c}\text { Temperature } \\
\left({ }^{\circ} \mathrm{C}\right)\end{array}$} & \multicolumn{3}{|c|}{ Particle size for holding time $(\mu \mathrm{m})$} \\
\hline & & 10 minutes & $\begin{array}{c}20 \\
\text { minutes }\end{array}$ & $\begin{array}{c}30 \\
\text { minutes }\end{array}$ \\
\hline \multirow{3}{*}{1} & 750 & $1-1.5$ & $1-1.5$ & $2-2.5$ \\
\hline & 780 & $1-1.5$ & $1.5-2$ & $2-2.5$ \\
\hline & 810 & $1.5-2$ & $2-2.5$ & $2.5-3$ \\
\hline \multirow{3}{*}{4} & 750 & $\begin{array}{c}1-1.5 \\
L-5, D-1\end{array}$ & $1.5-2$ & $2.5-3$ \\
\hline & 780 & $1-1.5$ & $1-1.5$ & $2-3$ \\
\hline & 810 & $1-1.5$ & $1-1.5$ & $\begin{array}{c}2-2.5 \\
L-12, D-1\end{array}$ \\
\hline \multirow{3}{*}{7} & 750 & $1-1.5$ & $1.5-2$ & $2.5-3$ \\
\hline & 780 & $1.5-2$ & $2-2.5$ & $2-2.5$ \\
\hline & 810 & $\begin{array}{c}1-1.5 \\
L-8, D-1.5 \\
\end{array}$ & $1-1.5$ & $2-2.5$ \\
\hline \multirow{3}{*}{19} & 750 & $1-1.5$ & $1-1.5$ & $1.5-2$ \\
\hline & 780 & $1-1.5$ & $1.5-2$ & $2-2.5$ \\
\hline & 810 & $1-1.5$ & $1-1.5$ & $2-2.5$ \\
\hline \multirow{4}{*}{21} & 750 & $1-1.5$ & $1.5-2$ & $2-2.5$ \\
\hline & 780 & $1-1.5$ & $1-1.5$ & $1.5-2$ \\
\hline & & $1-1.5$ & & \\
\hline & 810 & $\begin{array}{l}L-10 \\
D-1.5\end{array}$ & $1-1.5$ & $2-2.5$ \\
\hline \multirow{3}{*}{23} & 750 & $1.5-2$ & $2-2.5$ & $2-2.5$ \\
\hline & 780 & $1-1.5$ & $1.5-2$ & $2-2.5$ \\
\hline & 810 & $1-1.5$ & $1-1.5$ & $\begin{array}{c}2-2.5 \\
L-5, D-1 \\
\end{array}$ \\
\hline
\end{tabular}

$L=$ length of needle-shaped $\mathrm{TiB}_{2}$ particles. $D=$ diameter of needle-shaped $\mathrm{TiB}_{2}$ particles.

Also, the distribution of $\mathrm{TiB}_{2}$ particles at different locations for less holding times and pouring temperatures was found to be low, which is tabulated in Tables 1 and 2 .

\section{Conclusions}

The $\mathrm{TiB}_{2}$ particles were found to be more at location 23 because of the very high cooling rate.

The $\mathrm{TiB}_{2}$ particles were found more at locations 23 and 21 due to the very high turbulence. When the circulation of the fluid is more, the fluidity is also more.

Also, the tribological characteristics showed significant improvement on the basis of hardness. However, the reinforced particles get trapped quickly when the cooling rate was very high at these locations.

\section{Data Availability}

No data were used to support this study.

\section{Conflicts of Interest}

The authors declare that they have no conflicts of interest.

\section{References}

[1] S. Parasuraman, I. Elamvazuthi, G. Kanagaraj, E. Natarajan, and A. Pugazhenthi, "Assessments of process parameters on cutting force and surface roughness during drilling of
AA7075/TiB2 in situ composite," Materials, vol. 14, no. 7, Article ID 1726, 2021.

[2] G. Li, Y. Qu, Y. Yang, Q. Zhou, X. Liu, and R. Li, "Improved multi-orientation dispersion of short carbon fibers in aluminum matrix composites prepared with square crucible by mechanical stirring," Journal of Materials Science \& Technology, vol. 40, pp. 81-87, 2020.

[3] G. F. Aynalem, "Processing methods and mechanical properties of aluminium matrix composites," Advances in Materials Science and Engineering, vol. 2020, Article ID 3765791, 19 pages, 2020.

[4] R. Purohit, M. M. U. Qureshi, and B. Kumar, "Effect of forging on aluminum matrix nano composites: a review," Materials Today: Proceedings, vol. 4, no. 4, pp. 5357-5360, 2017.

[5] C. Prakash, S. Singh, S. Sharma et al., "Fabrication of aluminium carbon nano tube silicon carbide particles based hybrid nano-composite by spark plasma sintering," Materials Today: Proceedings, vol. 21, no. 1, pp. 1637-1642, 2020.

[6] P. Senthil Kumar, V. Kavimani, K. Soorya Prakash, V. Murali Krishna, and G. Shanthos Kumar, "Effect of TiB2 on the corrosion resistance behavior of in situ $\mathrm{Al}$ composites," International Journal of Metalcasting, vol. 14, no. 1, pp. 84-91, 2020.

[7] M. Hadian, H. Shahrajabian, and M. Rafiei, "Mechanical properties and microstructure of $\mathrm{Al} /(\mathrm{TiC}+\mathrm{TiB} 2)$ composite fabricated by spark plasma sintering," Ceramics International, vol. 45, no. 9, pp. 12088-12092, 2019.

[8] C. Mallikarjuna and S. M. Shashidhara, Proceedings of the World Congress on Engineering and Computer Science, San Francisco, CA, USA, 2007.

[9] Y. Shadangi, S. Sharma, V. Shivam et al., "Fabrication of Al$\mathrm{Cu}-\mathrm{Fe}$ quasicrystal reinforced 6082 aluminium matrix nanocomposites through mechanical milling and spark plasma sintering," Journal of Alloys and Compounds, vol. 828, Article ID 154258, 2020.

[10] I. Dinaharan and E. T. Akinlabi, "Low cost metal matrix composites based on aluminum, magnesium and copper reinforced with fly ash prepared using friction stir processing," Composites Communications, vol. 9, pp. 22-26, 2018.

[11] K. Niranjan and P. R. Lakshminarayanan, "Optimization of process parameters for in situ casting of $\mathrm{Al} / \mathrm{TiB} 2$ composites through response surface methodology," Transactions of Nonferrous Metals Society of China, vol. 23, no. 5, pp. 12691274, 2013.

[12] P. S. Kumar, P. R. Lakshminarayanan, and R. Varahamoorthi, "Effect of holding time of the Al/TiB2 melt at the pouring temperature on the formation and size of TiB2 particles formed," Journal of Advanced Microscopy Research, vol. 11, no. 2, pp. 140-144, 2016.

[13] S. Suresh, N. Shenbag, and V. Moorthi, "Aluminium-Titanium diboride (Al-TiB2) metal matrix composites: challenges and opportunities," Procedia Engineering, vol. 38, pp. 89-97, 2012.

[14] G. Elango and B. K. Raghunath, "Tribological behavior of hybrid (LM25Al + SiC+ TiO2) metal matrix composites," Procedia Engineering, vol. 64, pp. 671-680, 2013.

[15] V. Mohanavel, K. Rajan, S. Arul, and P. V. Senthil, "Study on microstructure and mechanical behavior of particulate reinforced aluminum matrix composites (PRAMCS)," International Journal of Advances in Engineering \& Technology, vol. VII, no. 1, p. 253, 2016 -March 252.

[16] M. R. Roshan, T. Mousavian, H. Ebrahimkhani, and A. Mosleh, "Fabrication of Al-based composites reinforced with Al2O3-Tib2 ceramic composite particulates using 
vortex-casting method," Journal of Mining and Metallurgy, Section B: Metallurgy, vol. 49, no. 3, pp. 299-305, 2013.

[17] X. Huang, Z. Zhao, L. Zhang, and J. Wu, "The effects of ultrahigh-gravity field on phase transformation and microstructure evolution of the TiC-TiB2 ceramic fabricated by combustion synthesis," International Journal of Refractory Metals and Hard Materials, vol. 43, pp. 1-6, 2014.

[18] M. Selvaganesan and S. Suresh, "Production and characterization of $\mathrm{Al}$ 6061- $\mathrm{TiB}_{2}$ metal matrix composites," International Journal of Engineering Research and Technology, vol. 2, no. 11, 2013.

[19] H. B. Michael Rajan, S. Ramabalan, I. Dinaharan, and S. J. Vijay, "Synthesis and characterization of in situ formed titanium diboride particulate reinforced AA7075 aluminum alloy cast composites," Materials \& Design, vol. 44, pp. 438-445, 2013.

[20] D. Yadav and R. Bauri, "Friction stir processing of Al-TiB2 in situ composite: effect on particle distribution, microstructure and properties," Journal of Materials Engineering and Performance, vol. 24, no. 3, pp. 1116-1124, 2015.

[21] H. Itoh, S. Naka, T. Matsudaira, and H. Hamamoto, "Preparation of TiB2 sintered compacts by hot pressing," Journal of Materials Science, vol. 25, no. 1, pp. 533-536, 1990.

[22] L. Lu, M. O. Lai, and F. L. Chen, "Al-4 wt\% Cu Composite reinforced with in-situ $\mathrm{TiB}_{2}$ particles," Acta Materialia, vol. 45, pp. 4297-4309, 1997.

[23] A. R. Kennedy, A. E. Karantzalis, and S. M. Wyatt, "The microstructure and mechanical properties of $\mathrm{TiC}$ and $\mathrm{TiB}_{2}-$ reinforced cast metal matrix composites," Journal of Materials Science, vol. 34, no. 5, pp. 933-940, 1999.

[24] J. H. Abboud and D. R. F. West, "Microstructure of Ti-TiB2 surface layers produced by laser particle injection," Journal of Materials Science Letters, vol. 13, no. 6, pp. 457-461, 1994.

[25] M. Wang, D. Chen, Z. Chen et al., "Mechanical properties of in-situ TiB2/A356 composites," Materials Science and Engineering $A$, vol. 590, pp. 246-254, 2014.

[26] A. Haiter Lenin, S. C. Vettivel, T. Raja, L. Belay, and S. C. E. Singh, "A statistical prediction on wear and friction behavior of $\mathrm{ZrC}$ nano particles reinforced with $\mathrm{Al} \mathrm{Si} \mathrm{com-}$ posites using full factorial design," Surfaces and Interfaces, vol. 10, pp. 149-161, 2018.

[27] J. S. Park, J. H. Yun, Y. D. Park, Y. H. Park, K. M. Cho, and I. M. Park, "Effect of cooling rate on mechanical and electrical properties of $\mathrm{Cu}-\mathrm{TiB}_{2}$ by turbulent in-situ mixing process," Solid State Phenomena, Trans Tech Publications, vol. 119, Zurich, Switzerland, 2007.

[28] P. Senthilkumar, R. Manimaran, and Y. Krishna Reddy, "Evaluation of mechanical properties of hybrid Al7009 nanocomposite," Energy Sources, Part A: Recovery, Utilization, and Environmental Effects, vol. 43, no. 2, pp. 216-224, 2018. 